\title{
CORRESPONDENCE
}

\section{EYE-RUBBING AND CONTACT LENSES}

\section{To the Editorial Committee of the BrITISH JouRnal OF OPHTHALMOLOGY}

SIRS,-In 1947 I first noticed a patient, a severe case of keratoconus, indulging in very vigorous eye-rubbing and from that time I have had this in mind. In 1956 (Brit. J. Ophthal., 40, 295), I summarized my experience of 92 cases of keratoconus, but omitted any reference to eye-rubbing as I was not then sure of its significance.

Irritability of the eyes on account of infection, allergic affections, or emotional stress as at school or at puberty, may induce eye-rubbing in anyone and, as a rule, no permanent harm ensues. If, however, the cornea is weakened by coincident or antecedent inflammation or, as is seen so frequently in my experience of keratoconus, it is thin centrally on account of conus posticus then the cornea may give way if subjected to persistent rubbing. It is first distorted and this may give rise to increasing astigmatism: as a rule the angle of the astigmatism is clearly related to the manner of eye-rubbing. Later the cornea stretches and typical keratoconus is produced. It might be thought that the rubbing is coincidental and not causal, but the large proportion of patients giving a history of habitual rubbing before the keratoconus appeared leaves little doubt that eyerubbing causes the cornea to give way and is also responsible for the progress of the condition. Very rarely indeed a normal cornea insulted by gross and persistent gouging and rubbing may follow the same course; one case actually developed severe hydrops of the corneae. It seems that keratoconus most commonly arises in patients affected by conus posticus who are also eye-rubbers.

To analyse in detail more than $\mathbf{3 0 0}$ cases will take a considerable time and there must be a further delay before publication. It has been put to me that, feeling reasonably certain of these facts as I now do, I ought to draw attention to them as quickly as possible so that patients may be warned against the dangers of eye-rubbing and ophthalmologists may be on the look-out for such cases.

MOORFIELDS EyE HoSPITAL, Yours faithfully,

HiGH HOLBORN, FREDERICK RIDLEY.

LONDON, W.C.1.

May 25, 1961.

\section{BOOK REVIEWS}

Optics. By K. N. Ogle. 1961. Pp. 265, 179 figs. Thomas, Springfield, Ill. (70s.)

This is a useful book which, while claiming to be an introduction to the ophthalmologist for the study of refraction and visual physiology, contains all, and perhaps even more than all he reasonably requires to know of optical theory. A book of this kind cannot by its nature contain much original thought. The merit of a new work on a subject already standardized in all its essentials can only lie in the method of presentation. The present volume is based on lectures given to ophthalmologists at the Mayo Clinic, and the method of the presentation of the subject fully justifies its publication. The subject is well covered with sections on the nature of the physical characteristics of light, 